\title{
Welfare effects of technology-based climate policies in liberalized electricity markets: seeing beyond total system cost
}

\author{
Sophie Maire ${ }^{1}$ (D) Philippe Thalmann ${ }^{1 *}$ and Frank Vöhringer ${ }^{1,2}$
}

\begin{abstract}
This paper is a contribution to assessing the Swiss energy transition, with an emphasis on the consequences of decommissioning the nuclear power plants for the electricity market and the whole economy. We expect that increased renewable generation and demand-side policies of the type already envisioned will not suffice to close the supply gap, so that Switzerland will have to rely on more imports of electricity, moving away from the export surpluses realized almost every year since 1910. As this reference scenario is contrary to desired energy security, a policy scenario is proposed in which net electricity trade is constrained to balance over the year and the supply gap is closed by relaxing the existing restrictions on gas-fired power plants. One constraint replaces another one, so that the impacts are not obvious. Furthermore, the prices of electricity and natural gas evolve quite differently through time and depend on climate and energy policy. We use a modeling framework coupling a detailed representation of electricity generation and an encompassing representation of the macro-economy to compare these scenarios in terms of both total system cost and welfare. Both indicators favor the reference scenario without gas-fired power plants in spite of its higher marginal costs for electricity. The welfare loss of the policy scenario is small, though, much smaller than the increase in total system cost. This shows that a coupled bottom-up top-down modeling framework assessing the welfare effect of policies can yield very different results from those of an energy system model assessing their impact on total system cost.
\end{abstract}

Keywords: Climate policy, Energy policy, Electricity markets, Technology restrictions, Soft-link coupling, General equilibrium model, Bottom-up model

\section{Introduction}

This paper is a contribution to assessing the Swiss energy transition, like the other articles in this special issue, but with a different focus. Its emphasis is on the consequences for the electricity market and the whole economy of decommissioning the nuclear power plants. They contributed $31.7 \%$ of domestic electricity generation in 2017, the rest being essentially provided by hydropower plants (59.6\%) (Swiss Federal Office of Energy, 2018). If the nuclear power plants are shut off soon (we assume that all plants are off the grid by 2035), this leaves a sizable gap, which cannot be filled by renewable generation only. The only other plausible candidate for

\footnotetext{
* Correspondence: philippe.thalmann@epfl.ch

'Laboratory of Environmental and Urban Economics (LEURE), Ecole

Polytechnique Fédérale de Lausanne (EPFL), Lausanne, Switzerland

Full list of author information is available at the end of the article
}

domestic replacement is gas-fired power generation. Alternatively, more electricity could be imported. Both options have large downsides. They increase Switzerland's energy imports and the first accepts a new source of large $\mathrm{CO}_{2}$ emissions.

This paper simulates scenarios corresponding to each option and compares them. Its main innovation is to include in the scenarios another feature of the Swiss energy transition-gradual electricity market liberalization. This calls for a rather detailed representation of the electricity market, such as only bottom-up models can provide. At the same time, economy-wide consequences and impacts on total $\mathrm{CO}_{2}$ emissions are central concerns, which call for a macroeconomic model. Therefore, a new modeling framework was developed for the purpose of simulating these scenarios, by coupling the dynamic TIMES electricity supply model CROSSTEM-CH 
with the dynamic computable general equilibrium (CGE) model GENESwIS. With market liberalization, the coupling of the two models may not rely on the commonly applied exchange of average costs and prices, but needs to represent marginal cost pricing on electricity markets instead. An unexpected outcome of our double-legged approach is that total system costs and welfare effects yield quite different assessments of the alternatives. This result is closely related to mechanisms around marginal cost pricing and demonstrates the value added by our coupling approach.

Switzerland, with its energy policy in full transition, is an interesting case study. The Energy Strategy 2050, elaborated by the Swiss Federal Council, aims to warrant an energy supply for Switzerland that is cost-effective, respectful of the environment, and secure. The policy focus is on the improvement of energy efficiency and the promotion of renewables. This focus is planned to be achieved, from 2020, through market-based policies. The Swiss electricity market is partly liberalized and to be further integrated within the larger European market. Further steps of market liberalization in Switzerland are being discussed, namely to extend to private households and small firms the possibility to choose their electricity supplier.

Following the Fukushima nuclear disaster in 2011, the Swiss Federal Council decided to decommission nuclear power plants at the end of their safe operational lifetime (the nature and time scale of which is yet to be agreed upon) without replacing them by newer generation nuclear plants. Switzerland has been now accustomed to a largely $\mathrm{CO}_{2}$-free electricity generation and has vouched to domestically reduce its total greenhouse gas emissions by $30 \%$ in 2030 compared with 1990 .

The Energy Perspectives 2050, commissioned by the Federal Office of Energy after the 2011 decision to gradually abandon nuclear power, drafted three energy policy scenarios, resulting in different demand paths, as well as three electricity supply options to answer electricity demands taking nuclear phase-out into account (Prognos, 2012). These supply options are the following: (1) gasfired power plants, (2) gas-fired power plants and renewables, and (3) renewables with the help of electricity imports. Prognos (2012) simulated this set of scenarios with a bottom-up model performing an "if-then" type of analysis: Exogenous border conditions on energy prices, population, and GDP growth drive the model, while the different policy measures and objectives modify the possible options and pathways.

Only the direct costs of the energy system were estimated by Prognos in their very detailed bottom-up approach. Therefore, Ecoplan (2012) was mandated to assess the economic effects of these scenarios. With their CGE model, they simulated climate and energy policies sufficient to attune energy demands and $\mathrm{CO}_{2}$ emissions with Prognos' projections and estimated macroeconomic impacts. All simulations were conducted with the electricity supply option that includes gas-fired power plants.

Gas is, in many countries with existing coal-fired power plants, considered to be an improvement over coal. However, in Switzerland, gas-fired power plants would drastically increase $\mathrm{CO}_{2}$ emissions from electricity generation. These additional emissions would have to be compensated by stronger efforts in other sectors of the Swiss economy. Current legislation, mainly the federal law on the reduction of $\mathrm{CO}_{2}$ emissions (" $\mathrm{CO}_{2} \mathrm{Law}$ "), stipulates that fossil thermal power plants will only be approved if they fully compensate their $\mathrm{CO}_{2}$ emissions, of which at least half in the country. This is prohibitive and keeps Swiss electricity firms from investing in gasfired power plants in Switzerland. Instead, they invest in foreign gas-fired power plants ${ }^{1}$. For the gas-fired power plants supply options of the Energy Strategy to materialize, the domestic compensation condition of the $\mathrm{CO}_{2}$ Law might have to be relaxed or alleviated through carbon capture and sequestration.

In order to keep electricity generation $\mathrm{CO}_{2}$-free, Switzerland could bet on renewables. However, many economic, administrative, and socio-political barriers are slowing down their deployment (Swiss Federal Office of Energy, 2012). Alternatively, Switzerland could rely on electricity imports from its neighbors. From 1910 until 2004, Switzerland exported more electricity than it imported. Since then, the balance oscillates in a band of $\pm 10 \%$ of final electricity consumption (Swiss Federal Office of Energy, 2018). A larger excess of imports would raise concerns about energy security.

This paper is not the first to examine the consequences of the Swiss nuclear phase-out. Some studies used bottom-up models (Prognos, 2012; Weidmann, Kannan, \& Turton, 2012), which are, by construction, very detailed technically but model only partial equilibrium. They report variations on total system cost (only direct costs). Other studies used CGE models, with the electricity generation production function modified to yield discrete technological responses (Böhringer, Wickart, \& Müller, 2003; Bretschger \& Zhang, 2017). They are able to analyze the effects on welfare (Hicks equivalent variation) and the economy as a whole, as well as changes in the overall excess burden of the tax system. However, their hybrid representation of electricity generation options has limited technological detail compared to rich bottom-up models.

\footnotetext{
${ }^{1}$ For example, BKW invested in gas-fired power plants in Italy, and Alpiq in the Czech Republic, Hungary, and Italy.
} 
In this paper, we combine the bottom-up and topdown approaches in a single framework called ELECTRA-CH. It was developed specifically to analyze the Swiss electricity market. It is composed of the dynamic TIMES electricity supply model CROSSTEM$\mathrm{CH}$ and the dynamic CGE model GENESwIS. The two models are coupled through an iterative soft link (Drouet et al., 2005; Martinsen, 2011; Rausch \& Mowers, 2014; Schäfer \& Jacoby, 2005; Wene, 1996), which consists in exchanging a chosen set of variables and solving the models iteratively until convergence is reached on a given criterion. The technology-rich CROSSTEM-CH computes cost-efficient electricity generation, which determines the electricity production function and costs for GENESwIS. In turn, GENESwIS sends back endogenous electricity demands and factor and intermediate input prices variation due to general equilibrium effects.

We use this framework to simulate two scenarios for the replacement of the decommissioned nuclear power plants, inspired by the supply options of the Energy Perspectives: (1) a reference scenario that maintains the restrictions on gas-fired power plants and accepts large net electricity imports, and (2) a policy scenario that lifts the restrictions on gas-fired power plants and bans net electricity imports. The policy landscape is the same in both scenarios, including strengthened market-based energy and climate policies, liberalization of electricity markets, and the decommissioning of all nuclear power plants after 50 years of operation.

The paper is organized as follows: Section 2 presents the ELECTRA-CH framework, Section 3 describes the scenarios, Section 4 discusses the results, and Section 5 concludes.

\section{Modeling framework}

\subsection{The component top-down model GENESwIS}

GENESwIS is a dynamic CGE model of the Swiss economy designed to analyze energy and environmental policies (Maire, 2016; Maire, Pattupara, Kannan, Vielle, \& Vöhringer, 2015; Vöhringer, 2012). Agents are represented as rational and forward-looking over the time horizon 2010-2050. Households maximize their utility with fixed preferences and a budget constraint. Firms maximize their profit with fixed production technologies and perfect competition. The government collects taxes on income, value-added, mineral oil, $\mathrm{CO}_{2}$, and electricity and uses the revenues for lump-sum transfers (social benefits) and public goods provision. The budget is stabilized through adjustment of the income tax rate, in order to keep public goods provision constant. Domestic and foreign goods are assumed to be imperfect substitutes in the Armington (1969) tradition. Non-satiation in consumption implies that demand must equal supply in all markets under flexible positive prices.

Capital is modeled as putty-clay in order to replicate the rigid character of investment decisions and the crowding out of investments. Thus, capital, once it is invested in one sector (industry, services or electricity), cannot be transformed into capital for another sector. Investments are treated as exclusively domestic. Labor supply is flexible given that agents can choose between labor and leisure, but internationally immobile.

The energy sector is as disaggregated as necessary for global energy and environmental policy analysis: electricity, natural gas distribution, district heating, refineries, and three transport sectors (rail, road, other). Fossil energy carriers are differentiated into nuclear fuel, natural gas, crude oil (all three only imported), light heating oil, petrol, and diesel. Nonenergy industries are separated into aggregates considering their possible importance in the formation of capital for the electricity sector and their affiliation to different carbon pricing schemes (ETS, $\mathrm{CO}_{2}$ tax): agriculture, cement and concrete, construction, metals, other ETS sectors, rest of industry, and rest of services.

The electricity sector is split into Electricity Generation and Electricity Transport and Distribution to permit the differentiation between wholesale electricity and retail electricity prices. Wholesale electricity is either produced by the Electricity Generation sector or imported. It is demanded by the Electricity Transport and Distribution sector or exported. Retail electricity, transported and distributed, is demanded as an intermediate input and for consumption through three different types of uses (appliances, transport, heating), with demand-side substitution opportunities represented separately for each of these uses.

The nested CES production technologies, except for electricity and rail transport, follow a standard KLEM structure where energy trades off with the factor composite at the second level. The energy nest does not allow for much substitution between the three different types of energy use: transport, appliances, and heat. However, within these types of energy uses, different fuels or types of production can be substituted for each other. The transport nest specifies trade-offs between own transport (including the possibility to switch to electro-mobility) and the different modes of transport services. Own transport is constituted of transport fuels and electro-mobility. The heating nest is composed of inputs of natural gas, light heating oil, district heating, and retail electricity. An input from construction is included to represent the option to reduce energy demand for heating through insulation. 
The nesting for energy demand in consumption replicates the same ideas.

For additional information on the GENESwIS component model, such as nesting trees, elasticities of substitution, dynamic calibration, and other data, please consult Section 2.2 in Maire, Pattupara, et al. (2015).

\subsection{The component bottom-up model CROSSTEM-CH}

The Cross-Border TIMES Electricity Model CROSSTEM is a technology-rich dynamic bottom-up optimization model of the electricity system in Switzerland and its four neighboring countries, developed in the TIMES framework. TIMES (Loulou, Goldstein, Remne, Kanudia, \& Lehtila, 2005) is a perfect foresight model in 5-year time periods that, given a comprehensive set of technologies, allows users to minimize the cost of the technology mix over the time horizon, matching a given demand and considering a set of constraints. It displays a high level of technological detail, including operational and maintenance costs, investment costs, fuel costs, lifetime, construction time, renewable potential, and decommissioning. There are around 200 technologies ${ }^{2}$ interconnected by more than 60 commodities $^{3}$ to define the whole electricity system. The technologies in the model include a range of electricity power plants, interconnectors for electricity trade between regions, ad hoc electricity distribution grid, and storage technologies (pumped hydro storage). CROSSTEM-CH does not entail subsidies or feed-in tariffs for renewable technologies.

CROSSTEM (Pattupara \& Kannan, 2016) was developed from the existing STEM-E model described by Kannan and Turton (2011). It has time slices that reflect the variability of electricity demand across the day (hourly), different types of days (weekday, Saturday, Sunday), and the seasons. Thus, the $8760 \mathrm{~h}$ of a year are represented with 288 representative hours (time slices). End-use electricity demands in these slices are inelastic and exogenous. Electricity load curves from the year 2010 are adopted for the entire model horizon. CROSSTEM does not model real end-uses (energy useful demands) as some other TIMES models do.

For the analysis in this paper, we use the Swiss module of the CROSSTEM model-CROSSTEM-CH. Electricity import and export prices are set exogenously and taken from the ADAM project (Jordan, Huitema, Van Asselt, Rayner, \& Berkhout, 2010). The model optimizes trade

\footnotetext{
${ }^{2}$ Process technologies in TIMES include a range of technologies, which are classified into the following groups according to their role in the energy system: electric power plants (ELE), storage plants (STG), interregional exchange (IRE), demand devices (DMD), renewables (RNW), mining (MIN), imports/resources (IMP).

${ }^{3}$ Commodities can also be classified as energy (NRG), emissions

(ENV), demand (DEM), material (MAT), and financial (FIN).
}

revenue within the year: importing when it needs to or when exogenous foreign prices are low and exporting when prices are high. This has resulted in trade volumes being equal in the past, and the creation of a positive trade revenue.

The model is calibrated for 2010. For more detail on CROSSTEM-CH, see Pattupara (2016) and Loulou et al. (2005).

\subsection{The coupling procedure}

\subsubsection{General approach and iteration process}

For bottom-up top-down coupling, many approaches have been developed since Hoffman and Jorgenson (1977), each with its strengths and weaknesses (for a review of the methods, see e.g., Böhringer \& Rutherford, 2009). Few studies elaborate on the link between costs from bottomup models and prices in CGEs. Amongst those that do, assumptions differ, as the following examples show:

- Fortes, Pereira, Pereira, and Seixas (2014) link-as is most commonly done-total energy costs (average cost) variation from TIMES to energy prices in a CGE model.

- Martinsen (2011) links electricity marginal cost (weighted annual average) from a MARKAL model to wholesale electricity prices in a CGE model.

- Riekkola, Berg, Ahlgren, and Söderholm (2013) link the shadow price (marginal cost) of electricity from TIMES to the electricity price in a CGE model.

In our approach, we build on this stream of literature to model the transition from average to marginal cost pricing in a gradually liberalizing market. We couple GENESwIS and CROSSTEM-CH through an automated iterative soft link. Coupling through soft links allows keeping the integrity of the models while prioritizing the strengths of each model to compensate for the shortcomings of the other. Each model is solved iteratively with input information from the other model until convergence is reached on a given criterion.

Figure 1 depicts the exchange of information between the two models. Electricity generation costs and their components as well as export revenues and import costs are extracted from the CROSSTEM-CH model and translated for the CGE model into the wholesale electricity price and input shares for factors and commodities in the electricity generation cost function. The sectoral electricity demand quantities simulated by the GENESwIS model are then sent back to become inputs to the CROSSTEM-CH model. To account for relevant price and cost changes in the economy, factor and intermediate input prices from GENESwIS are fed to the 


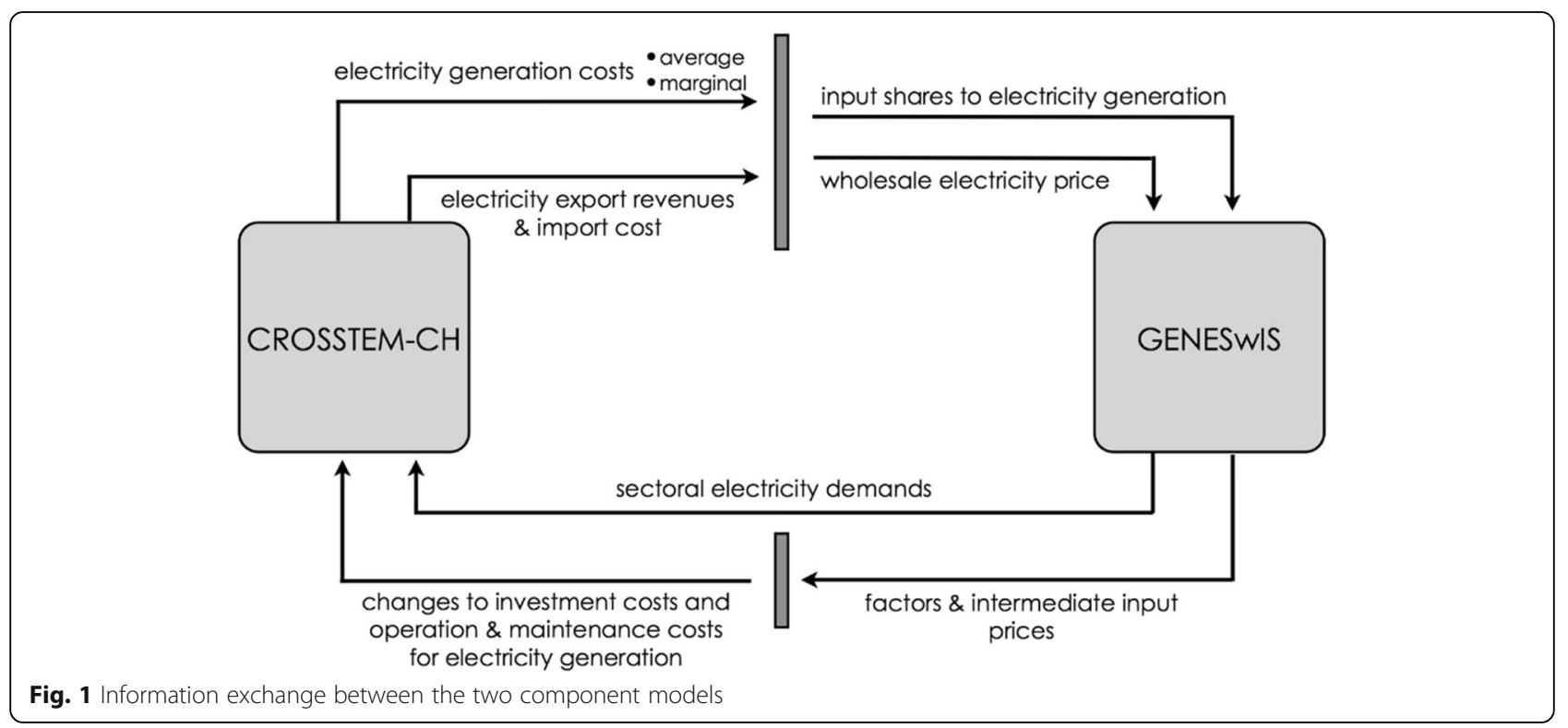

investment costs and operation and maintenance costs of the different technologies in the bottom-up model. This process of data transfer is repeated until the vector of quantities of total yearly electricity demands converges. It is initiated with a run of CROSSTEM-CH using baseline electricity demand projections from Prognos (2012) as exogenous input.

In the following subsections, we elaborate on the treatment of the variables to be exchanged between the models. We also describe the modifications implemented in each model such that they treat the information adequately.

\subsubsection{CROSSTEM-CH to GENESwIS-input shares and wholesale electricity price}

For information on electricity generation from CROSSTEM to be treated as direct input, the electricity generation production function of GENESwIS is set-up as a Leontief function. Its cost function can therefore be written as:

$$
C_{E L E}(P, Y, t)=Y_{E L E}(t) \cdot \sum_{t} \widetilde{q}_{i}(t) \cdot P_{i}(t)
$$

where $Y_{\mathrm{ELE}}(t)$ is the activity index variable of the electricity generation production function in period $t$, $P_{i}(t)$ represents the price variables, and $\tilde{q}_{i}(t)$ the quantities of the different inputs, indexed by $i$, entering electricity generation. Thus, no substitution is allowed between inputs, within one model run: their value shares are fixed. The production function for electricity generation in GENESwIS is thus determined by the cost shares optimized by CROSSTEM-CH in each iteration.
The quantities of the different inputs $\tilde{q}_{i}(t)$ are determined for each iteration ${ }^{4} k$, given the costs $\tilde{c}_{i}(t)$ from CROSSTEM-CH, taking into account the input price levels $P_{i}$ and the activity index of electricity generation $y_{\mathrm{ELE}}$ :

$$
\tilde{\mathrm{q}}_{\mathrm{i}}(\mathrm{t})=\frac{\tilde{\mathrm{c}}_{\mathrm{i}}(\mathrm{t})}{\mathrm{P}_{\tilde{\mathrm{i}}, \mathrm{k}-1}(\mathrm{t}) \cdot \mathrm{y}_{\mathrm{ELE}, \mathrm{k}-1}(\mathrm{t})}
$$

By calculating input quantities in this way, the wholesale electricity price $P_{\mathrm{ELE}}(t)$ reflects the average cost of the CROSSTEM-CH model. However, average cost pricing corresponds to a regulated market, whereas the Swiss and European electricity markets are already partly liberalized. As we have shown (Maire, Vöhringer, \& Thalmann, 2015), the effectiveness of energy policies is affected by assumptions about electricity market liberalization. It is difficult to predict whether and when all Swiss electricity consumers will be allowed to choose their supplier freely. We assume a gradual evolution to full liberalization in 2025. At that point, the wholesale electricity price will be equal to the long-term marginal cost computed in the bottom-up

\footnotetext{
${ }^{4}$ As prices cannot be fixed in a CGE model, the wholesale electricity price cannot be plugged directly into the model. However, prices in the CGE can be pushed to a given value by varying the inputs of the production function while keeping output constant. As prices and quantities vary continuously within a CGE run until equilibrium is reached, present iteration variables cannot be used to determine $\tilde{q}_{i}(t)$; values from the previous iteration must be taken as an approximation. Although prices at iteration $k-1$ might differ from prices at iteration $k$, once the framework converges, input prices converge as well. Likewise, as the convergence criterion is set on electricity demand, the electricity production index $Y_{\mathrm{ELE}}(t)$ is bound to have converged, as demand always equals supply in a CGE model.
} 


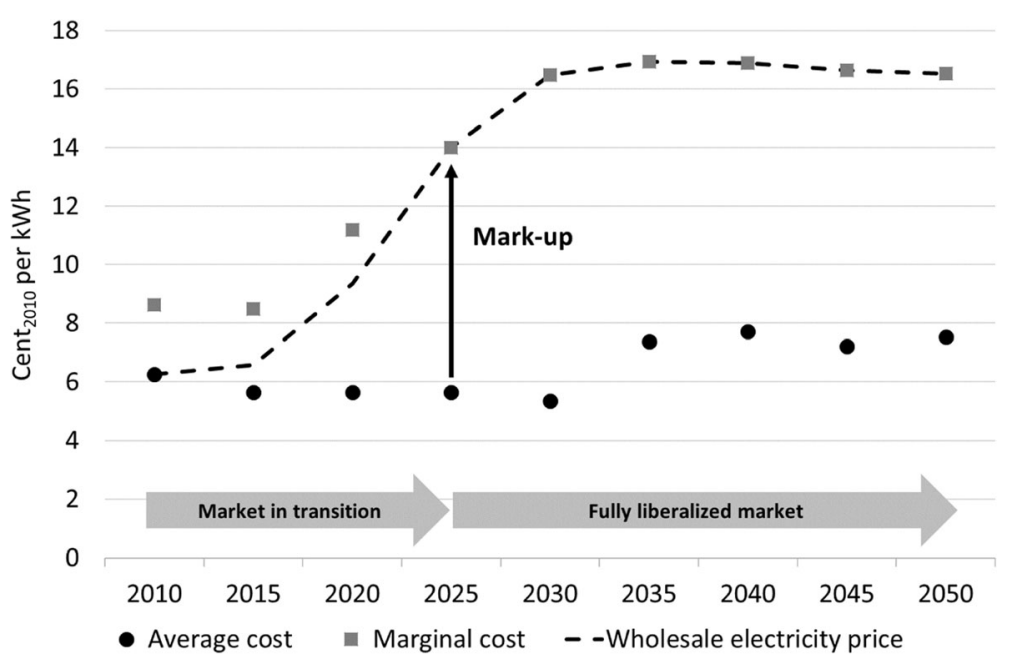

Fig. 2 Assumptions on market liberalization and implied wholesale electricity market price compared to annual average and marginal costs

model $^{5}$. From 2010 to 2025, the market is in transition and prices reflect an increasing importance of marginal cost pricing (see Fig. 2).

Marginal cost pricing in the wholesale market creates a profit, which provides an incentive for investment into new capacity. We hence introduce a profit mark-up on electricity production in the CGE model. The mark-up is calculated so that the price of wholesale electricity is pushed from the average cost, $\mathrm{AC}(t)$, given by the CROSSTEM-CH model, to the assumed market price ${ }^{6}$, $P_{m}(t):$

$$
\text { Profit mark-up }(t)=\frac{P_{m}(t)-\mathrm{AC}(t)}{\mathrm{AC}(t)}
$$

Average costs, mark-ups, and wholesale prices are averaged annually, i.e., they represent weighted averages over the 288 representative time slices of CROSSTEM$\mathrm{CH}$ per year.

In GENESwIS, all sectors display constant returns to scale. This is the common assumption in CGE models that do not explicitly model imperfect competition. Diminishing returns to scale enter the electricity

\footnotetext{
${ }^{5}$ The marginal cost in CROSSTEM-CH is the shadow price of the commodity balance and represents the increase in total system cost due to an additional unit of demand (Kannan \& Turton, 2011). It reflects all constraints and costs (incl. investment cost) and can therefore be seen as a long-term marginal cost, or marginal cost including scarcity rents for capacity. As the CGE model does not disaggregate the year into 288 time slices, the marginal cost is aggregated to an annual demand-weighted marginal cost. ${ }^{6}$ The assumptions on wholesale electricity market prices $P_{m}$ illustrated in Fig. 2 are the following: $P_{m}(2010)=$ historical value; $P_{m}(2015)=2 /$ $3 A C(2015)+1 / 3 M C(2015) ; P_{m}(2020)=1 / 3 A C(2020)+2 / 3 M C(2020)$ $P_{m}(t>2025)=M C(t)$.
}

generation function of GENESwIS through the coupling of the models, as the profit in the CGE model is equal to the producer surplus in the bottom-up model. This way, the framework considers sub-marginal rents and income effects from binding constraints in the bottom-up model. We do not, however, model imperfect competition, but marginal cost pricing in liberalized markets.

\subsubsection{GENESWIS to CROSSTEM-CH-electricity demands and factor prices}

GENESwIS comprehensively simulates economic responses of firms and households to the policy scenarios and to the changes in electricity generation technology and wholesale electricity price provided by the bottomup model. The resulting changes in electricity demand and in factor and commodity prices are passed on to the bottom-up model. This is done with price-variation coefficients ${ }^{7}$ applied to investment costs and operation and maintenance costs in CROSSTEM-CH. Fuel costs are set exogenously for both models, as we model Switzerland as a small open economy.

Yearly demands from GENESwIS are sent to CROSSTEM-CH and divided into the 288 time-slices with the help of historical load curves. To facilitate convergence, these electricity demands are sent as Gauss-Seidel combinations (Hageman \& Young, 1981; Labriet et al., 2010) of the previous demands. This is shown in Eq. (4), where $D_{k}^{\prime}$ is the demand introduced in CROSSTEM-CH in

\footnotetext{
${ }^{7}$ These coefficients are weighted averages of the price variations of the sectoral outputs and factors of production, with weights equal to the expenditure shares for each commodity or factor.
} 
iteration $k$, and $D_{k}$ is the demand estimated by the CGE model in that iteration.

$$
\mathrm{D}_{\mathrm{k}}^{\prime}=\alpha \mathrm{D}_{\mathrm{k}}+(1-\alpha) \mathrm{D}_{\mathrm{k}-1}^{\prime}
$$

The framework is deemed to have converged when electricity demand changes in the CGE model from one iteration to the next converge, i.e., when

$$
\frac{\sqrt{\sum_{t}\left(D_{k}(t)-D_{k-1}(t)\right)^{2}}}{\sqrt{\sum_{t} D_{k}^{2}(t)}} \leq 5 \cdot 10^{-5}
$$

\section{Scenarios}

The reference scenario, which we call the NoGAS scenario, maintains the policy restrictions that render gasfired power generation uneconomical. Hence, all domestic electricity must be produced with renewables. The excess of consumption over domestic production is covered by electricity imports. This corresponds to supply option E of the Swiss Energy Strategy.

The policy scenario, which we call the GAS scenario, is inspired by supply option $C$ of the Swiss Energy Strategy, in which electricity trade is constrained to balance over the year, but the successively decommissioned nuclear power plants can be replaced by gas-fired power plants. To make sure that gas-fired power plants get built in Switzerland, we have to relax the domestic compensation condition for their $\mathrm{CO}_{2}$ emissions. We assume that they join the Swiss emissions trading scheme (ETS), which will be linked to the European ETS.

Both scenarios include the following energy and climate policies, which are similar to those used in the other papers of this special issue:

- Nuclear power plants are phased-out at the end of an assumed lifetime of 50 years and not replaced by new-generation plants. As a result, no electricity is produced with nuclear technology after 2035.

- A tax is introduced on electricity consumption, amounting to $10 \%$ of the electricity retail price in 2020, increasing linearly to $50 \%$ in 2050 .

- The emission trading scheme (ETS) is linked to the European ETS. Switzerland is not expected to have a large impact on $\mathrm{CO}_{2}$ prices, which are thus exogenous, following projections by Prognos (2012).

- The $\mathrm{CO}_{2}$ tax on natural gas and heating fuels used by the non-ETS sectors and by households rises linearly from the existing $36 \mathrm{CHF} / \mathrm{t}$ in 2010 to $200 \mathrm{CHF} / \mathrm{t}$ in 2050. A share of 250 million $\mathrm{CHF}$ from its revenues is recycled through the Buildings Program, which subsidizes the energy refurbishment of buildings.
- $\mathrm{A} \mathrm{CO}_{2}$ tax is introduced in 2035 on transport fuels, starting at $50 \mathrm{CHF} / \mathrm{t}$ and rising linearly to $200 \mathrm{CHF} / \mathrm{t}$ in 2050.

These policies have the effect that energy-related $\mathrm{CO}_{2}$ emissions decrease by $52 \%$ in 2050 relative to 2010 or to 1.9 tons per capita.

\section{Results}

\subsection{Generation costs and technology mix}

Between 2019 and 2035, the five nuclear reactors are taken off the grid one by one. In the short and medium run, absent subsidies for renewable technologies, the CROSSTEM-CH model deems more cost-effective to import electricity rather than invest in expensive renewable technologies. By 2045, however, the expected electricity import prices ${ }^{8}$ are so high that renewable technologies such as solar PV and biomass become competitive.

In the GAS scenario, nuclear generation is replaced by base and flexible natural gas power plants. The flexible gas plants are installed to optimize import/export patterns and create maximum trade revenue. By 2050, solar PV becomes competitive due to technology learning and increasing natural gas and $\mathrm{CO}_{2}$ prices ${ }^{9}$ (Fig. 3a).

The total system cost (Fig. 3b) is noticeably lower for the reference (NoGAS) scenario than for the GAS scenario. The system saves mostly on variable costs: fuel cost (natural gas), taxes $\left(\mathrm{CO}_{2}\right.$ permits), and variable operation and maintenance costs. Despite Switzerland being a net electricity importer in the NoGAS scenario, the optimization of trade within the time slices permits the system to make a net surplus for most of the model

\footnotetext{
${ }^{8}$ Trade prices assumptions are specified for the four neighboring countries: France, Italy, Austria, and Germany. Yearly import prices are taken from the ADAM project (Jordan et al., 2010). Export prices are pegged to import prices. Note that the ADAM project does not build on the same IEA natural gas price projections as this paper, but a somewhat steeper price trajectory. We prioritized the harmonization of natural gas prices in CROSSTEM and GENESwIS with a reference scenario which has widely been used in Switzerland (Prognos, 2012). It is hardly possible with limited resources to correct ADAM output such that it would fully reflect our Swiss scenario assumptions. Consequently, the assumed international electricity trade prices are based on data, especially for gas prices, that are not fully consistent with our domestic scenario assumptions. One might advocate that these inconsistencies are dampened by the technology mix of the exporting countries, and that time-slice variations of import prices have a greater impact on technology choices than the average level of import prices (a description of the determination of time-slice variations of import prices can be found in Kannan and Turton (2011)). Notwithstanding, the example of gas prices shows how almost inevitably data consistency issues arise when different data sources are used, especially when domestic scenario requirements restrict the options for adjustments.

${ }^{9}$ Sources: gas price from International Energy Agency (2010) and $\mathrm{CO}_{2}$ prices following EU-ETS permit prices projections by Prognos (2012).
} 


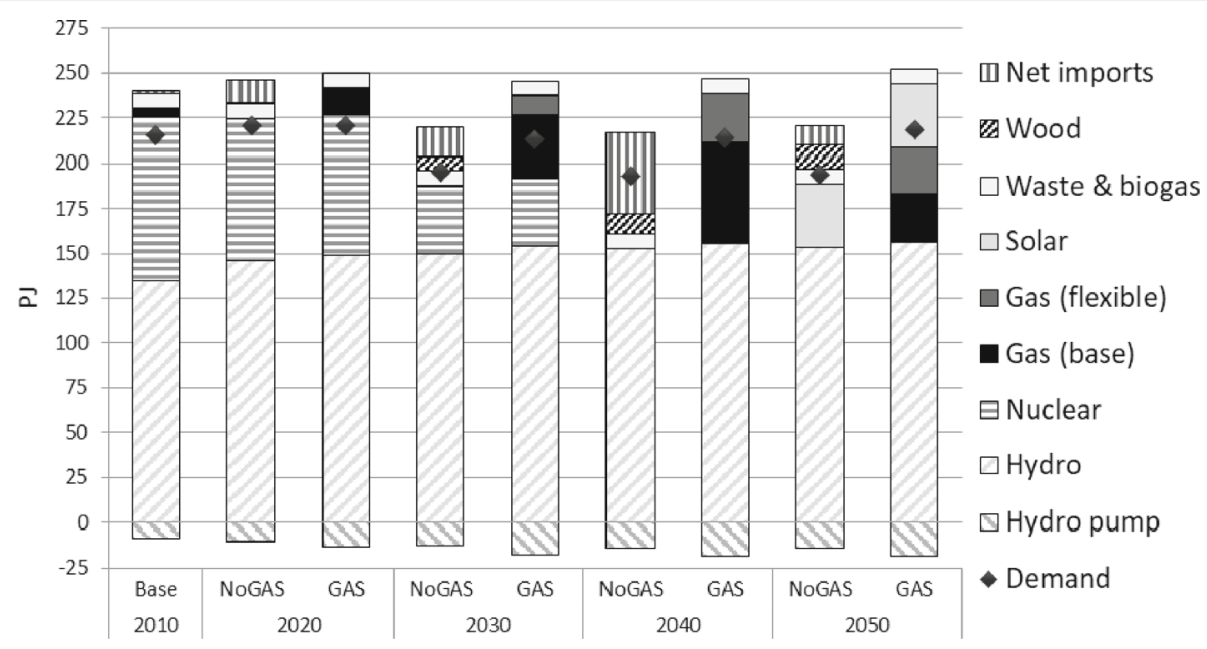

(a) Electricity generation mix

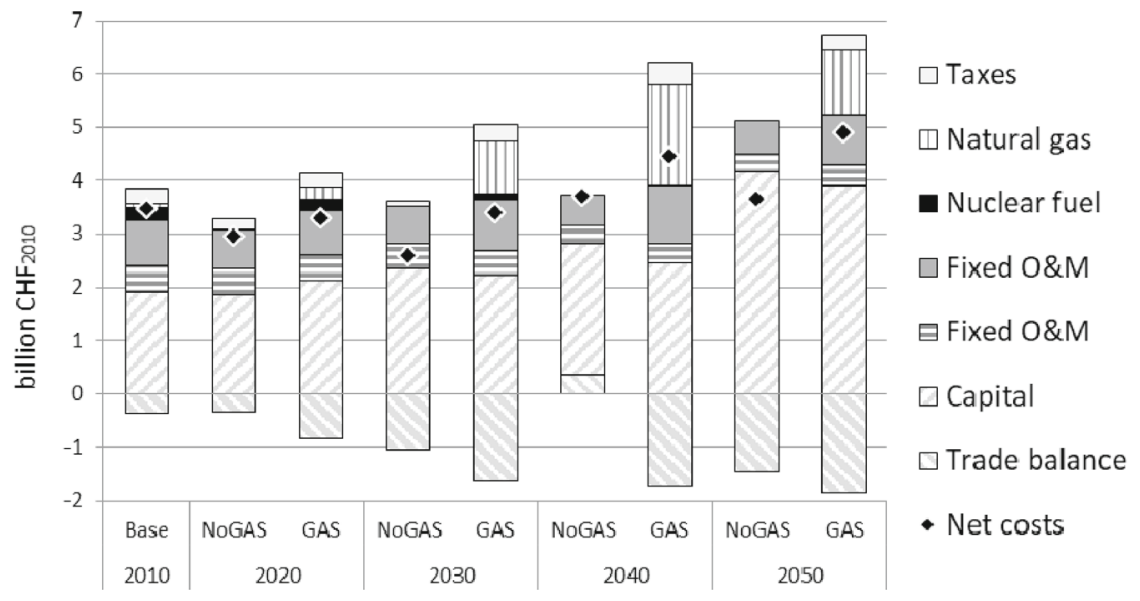

(b) Total undiscounted electricity system cost

Fig. 3 Electricity generation mix and system cost

horizon (except in 2040). The new gas-fired power plants of the GAS scenario raise its capital costs above those of the NoGAS scenario in the early years. This is reversed in later years, when more renewable capacities are installed in the NoGAS scenario.

As an aggregate over the whole modeling horizon, the present value of total system cost, computed with a discount rate of $4.5 \%$, is higher by 4.2 billion $\mathrm{CHF}_{2010}$ in the GAS scenario than in the NoGAS scenario.

\subsection{Electricity costs, prices, and demand}

In the short run (2015), the price of imported electricity is lower $\left(22.86 \mathrm{CHF}_{2010} / \mathrm{GJ}\right)$ than the marginal cost of gas-fired power plants $\left(38.4 \mathrm{CHF}_{2010} / \mathrm{GJ}\right.$ for an existing plant, and $28.5 \mathrm{CHF}_{2010} / \mathrm{GJ}$ for a new plant). It is therefore cheaper to import electricity than to rely on generation by gas-fired power plants. However, the price of imported electricity is assumed to rise much faster than that of gas, so that by 2020 , it is comparable to the marginal cost of gas-fired power plants, and from 2025 onwards, electricity generated by gas plants is cheaper than imported electricity (Fig. 4a). One consequence of the rapidly rising price of imported electricity is that yearly net electricity imports never become larger, in energy units, than the quantity of natural gas imported for electricity generation in the GAS scenario. Thus, the two scenarios can be considered similar with regard to energy security, depending on the relative assessment of supply risks of electricity and natural gas.

Given the assumed high electricity import prices, the wholesale price of electricity rises less in the GAS scenario than in the NoGAS scenario after 2020 (Fig. 4b). The electricity price paid by users includes the purchase of wholesale electricity, transport and distribution costs, and taxes. The prices of commodities and services 


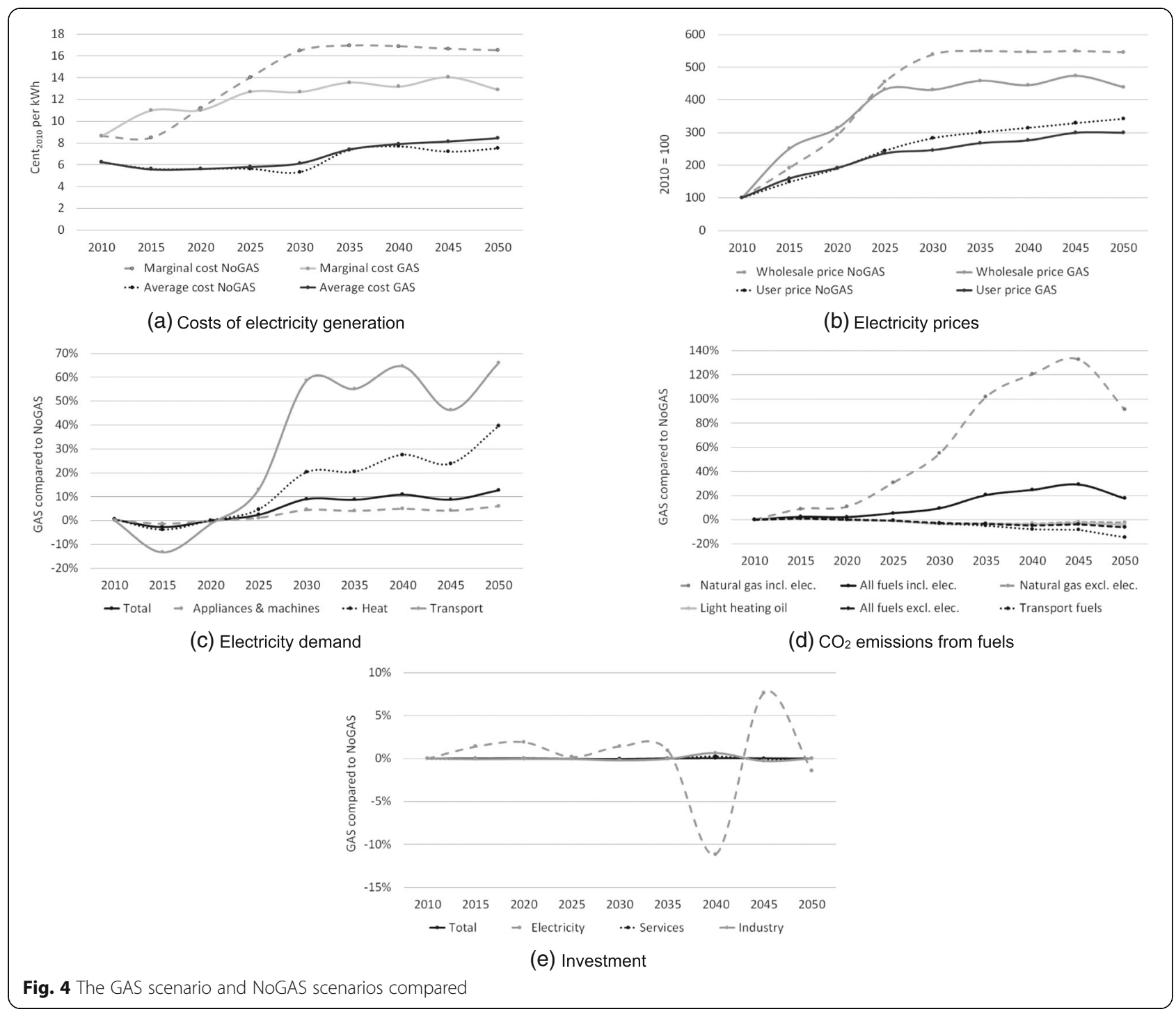

needed for transport and distribution are not affected by the restrictions on gas-fired power plants, and market-based policies are identical for both scenarios. Hence, end-user prices vary in the same way as wholesale electricity prices; however, this variation is dampened (Fig. 4b).

As an expected consequence of the smaller increase in end-user electricity price in the GAS scenario relative to the NoGAS scenario, relative total electricity demand increases (Fig. 4c). Electricity use for machines and appliances does not drift as strongly apart in the two scenarios as it is not easily substituted. For heating, however, electricity can replace natural gas, light heating oil, district heating, and better insulation. Figure $4 \mathrm{~d}$ shows that $\mathrm{CO}_{2}$ emissions from light heating oil and natural gas (excluding emissions from electricity generation) decrease slightly faster in the GAS scenario as a result of the substitution towards electricity for heating purposes. The differentials in electricity used and $\mathrm{CO}_{2}$ emitted for transportation are larger, but they may be overestimated, due to the high elasticity of substitution assumed for e-mobility in order to replicate the high penetration projections of Prognos despite a low base year value share of e-mobility (Prognos, 2012). Altogether, total fuel-related emissions excluding electricity generation decrease faster in the GAS scenario and lie about $6 \%$ below those of the reference scenario in 2050 .

$\mathrm{CO}_{2}$ emissions from natural gas are naturally much higher in the GAS scenario than in the reference scenario when the intermediate demand for electricity generation is included (Fig. 4d, Natural gas incl. elec.). This has the effect of slowing down the decrease in overall fuel-related $\mathrm{CO}_{2}$ emissions. These emissions end up $18 \%$ above those of the NoGAS scenario in 2050, but still 43\% below 2010. 
Electricity demand is about $10 \%$ higher in the GAS scenario than in the NoGAS scenario over 2030-2050, but total system cost is even more increased, so that the average cost is approximately $9 \%$ higher in the GAS scenario (Fig. 4a).

\subsection{Investment}

In the coupled framework, the CROSSTEM-CH model optimizes investment decisions for electricity generation, which determine yearly capital inputs in the electricity generation function of GENESwIS. GENESwIS simulates investment decisions and hence capital accumulation sufficient to satisfy the demand for capital in the electricity sector ${ }^{10}$. This affects investment and capital formation for the other sectors (industry and services) through crowding-out effects.

The GAS scenario with its new power plants requires more capital for electricity generation than the reference scenario (Fig. 4e). The impact on total investment is dampened by the fact that investment for electricity generation represents less than $2.5 \%$ of total investment and by a crowding-out effect for the other sectors through a higher relative price of capital. Investment in the industry sectors is more responsive than in services (relative to their size).

In the NoGAS scenario, the CROSSTEM-CH model invests about 10 PJ of solar photovoltaics capacity, which becomes competitive in 2045, instead of only in 2050 in the GAS scenario. This explains why total investment is $3.4 \%$ lower in the GAS scenario than in the NoGAS scenario in 2040, and 2.3\% higher in 2045 (Fig. 4e $)^{11}$.

\subsection{Welfare and consumption}

Imposing balanced electricity trade hurts the economy, even if gas-fired power plants are facilitated in compensation. Indeed, welfare is lower by $0.05 \%$ or 0.98 billion $\mathrm{CHF}_{2010}$ in present value in the GAS scenario than in the NoGAS scenario ${ }^{12}$. This result was not immediately predictable, as imported electricity is assumed to get relatively expensive after 2020 . Indeed, the marginal cost

\footnotetext{
${ }^{10}$ Capital is modeled as putty-clay, which means that once it is invested into one sector (industry, services, or electricity), it cannot be transformed into capital for another sector. Households optimize total welfare over the whole modeling horizon by choosing between consumption in a given year or saving to increase their utility at another time. Utilities of different years can be substituted to each other through an intertemporal elasticity of substitution of 0.2 .

${ }^{11}$ Such sharp transitions are intrinsic to bottom-up models. They are transmitted to the top-down model through the coupling.

${ }^{12}$ Changes in emissions related external effects are not considered in welfare assessment. They would increase the welfare cost of the GAS scenario. Consumer utility is higher in the NoGAS scenario in every year until shortly before 2050. The differential is greatest in 20152020, when imported electricity is still relatively cheap, also because it allows investment into domestic generation to be deferred to a period when it is more favorable.
}

of electricity is higher in the NoGAS scenario than in the GAS scenario from 2020 on, with a difference of 20 to $30 \%$ from 2030 on (Fig. 4a), precisely when consumers pay prices based on marginal costs (Fig. 2). The resulting lower electricity consumption (Fig. 4c) should lead to lower welfare in the reference NoGAS scenario. This reasoning forgets, however, that total energy system costs are a drain on overall consumption, on which welfare depends. These costs are higher by 4.2 billion $\mathrm{CHF}_{2010}$ in present value in the GAS scenario. Only about one fourth of this supplement is due to higher electricity consumption in the GAS scenario (it is higher by $5 \%$ on average, while total system costs are higher by 19\%). This can be seen from the higher average cost for the GAS scenario (Fig. 4a). Remember also that the investments in gas-fired power plants crowd out investment in the rest of the economy.

In short, the variations of total system cost and wholesale electricity price in the GAS scenario compared to the reference NoGAS scenario have opposing effects on welfare:

1. Lower marginal cost and hence wholesale price for electricity increases welfare through more electricity consumption.

2. Higher total system costs due to the fixed costs of gas-fired power plants lead to lower welfare.

The resulting combination is a loss in welfare, but much smaller than what would be expected from looking only at the increase in total system cost.

An important condition for this result is that profits are redistributed lump-sum to the representative household. Indeed, marginal cost pricing implies substantial profits (Fig. 5), which are welfare neutral under this assumption. Profits could as well be distributed to foreign owners or re-invested inefficiently. In Switzerland, the electricity utilities belong in majority to Swiss municipalities and cantons and contribute to their budgets, so that lump-sum profit recycling is actually a conservative assumption over the possibility that the profits could be used for lowering some distortionary tax.

\section{Conclusion}

This paper compares a policy scenario that leads to new gas-fired power plants replacing the gradually decommissioned nuclear power plants with a reference scenario that fills the virtual supply gap predominantly with electricity imports. Both have technology restrictions: the reference scenario bans gas-fired power plants; the policy scenario restricts electricity imports to not exceed exports in total over the year. The policy scenario gets the electricity at lower marginal cost (we assume that imported electricity is 


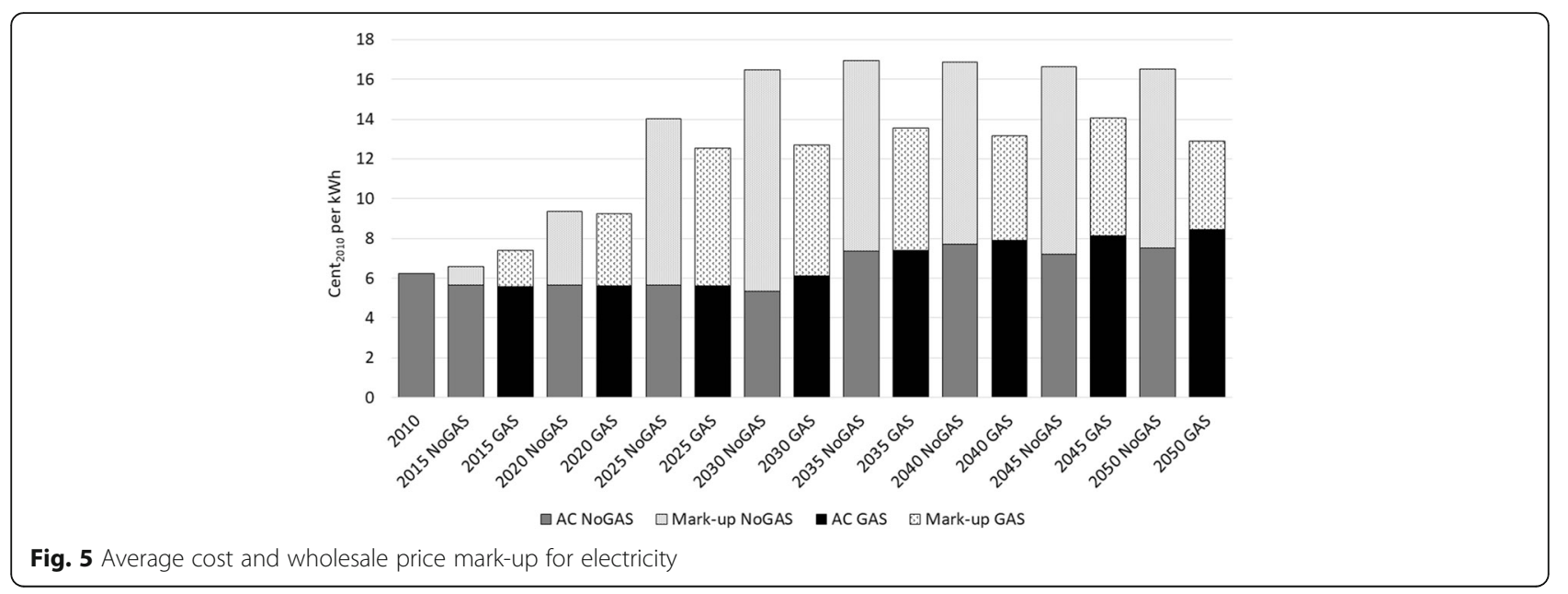

expensive), but requires substantial investment. If we focused on marginal costs, neglecting the role of fixed costs (which crowd out investment in other sectors and consumption), we would predict that the lower marginal costs of electricity in the policy scenario lead to higher household consumption and welfare ${ }^{13}$. If we focused instead on total system costs, as is common when working with energy system models, we might predict that taking advantage of "investment free" imports is the cheaper solution. Combining the two approaches yields an intermediate result: the reference scenario with electricity imports is preferable to the policy scenario with gas-fired power plants in spite of its higher marginal costs, but not as much as the difference in total system costs suggest. Policy preferences might thus rather depend on the assessment and weighting of other criteria such as domestic and gray $\mathrm{CO}_{2}$ emissions and import dependence on electricity versus natural gas.

Of course, we would not have these differing views if electricity consumers paid prices based on average rather than marginal costs. Therefore, the assumption of full market liberalization is essential for this result. Another important assumption is that the profits of the electricity utilities are redistributed lump-sum to households. If they were "wasted" or exported, the policy scenario, which has smaller mark-ups due to higher average and lower marginal costs, would look better. If the utilities' profits were used by their mostly public sector owners to reduce distortionary taxes, the reference scenario would look even better than it does. It would also gain from including the external costs of the gas-fired power plants in the welfare calculations.

\footnotetext{
${ }^{13}$ With this simple view, one would plead for average cost pricing over marginal cost pricing!
}

The simulation of scenarios with specific technology restrictions shows that they can have large effects on profits, which is particularly relevant with marginal cost pricing in liberalized markets. In the scenarios and with the cost assumptions of this paper, overall profits in Swiss electricity generation stay positive under marginal cost pricing, i.e., prices are high enough to cover the capital cost of the optimized generation park. This is, however, not a general result, and profits can turn negative when the variable costs of the marginal plant are very low, as is the case for many renewables. Given that our simulations bear positive profits, we do not address the consequences of less favorable profit situations for competitors and regulators in this paper. Anyway, with electricity markets being further liberalized, policy-induced variations in profit margins may not be overlooked. This calls for a framework that is able to assess the welfare impacts of the variation of electricity generation costs, wholesale prices, and sector profits, considering general equilibrium effects. In this context, the marginal cost-based coupling approach in the framework presented here is an important innovation.

Average and marginal costs of electricity varying in opposite directions are specific to our case study. It is indeed linked to the Swiss technology mix, and heavily reliant on projections for the prices of electricity and natural gas imports. If, contrary to our assumptions, electricity can always be imported at a lower price than the marginal generation cost with gas-fired power plants, then obviously, the policy scenario with the restriction on imports and the facilitation of gasfired power plants is even less attractive. Our conclusions are relevant for all situations where marginal and average cost behave differently, which is likely when the technology mix is composed of largely depreciated plants and marginal (new) technologies are relatively expensive. 


\section{Abbreviations}

CGE: computable general equilibrium; CHF: Swiss Franc; CROSSTEM: Crossborder TIMES Electricity Model; ETS: emissions trading scheme; O\&M: operation and maintenance; PJ: petajoule

\section{Acknowledgements}

We thank Rajesh Pattupara, Kannan Ramachandran, and Hal Turton from the Paul Scherrer Institute for their modeling work on the CROSSTEM-CH model and important project contributions which have helped us implement the coupling approaches. We also thank Rajesh Pattupara for his help with retrieving and deciphering the CROSSTEM-CH result files. Finally, we thank three anonymous referees, who lead us to substantially revise the paper.

\section{Authors' contributions}

All authors contributed to the idea and concept of the paper. The GENESwIS model had been developed by FV and modified and further developed by SM- with FV's help - in view of the coupling with CROSSTEM-CH and to adequately analyze electricity markets. The authors do not claim any intellectual property on the CROSSTEM-CH model, which was developed at the Paul Scherrer Institute. The coupling algorithm was conjointly discussed and then implemented by SM. The data analysis was conducted by SM, and the results were discussed amongst all authors. The lead in paper writing was with SM, assisted by FV and PT. The lead in revising the paper was with PT. All authors read and approved the final manuscript.

\section{Funding}

This work was funded by the Research Program Energy-Economy-Society of the Swiss Federal Office of Energy (SFOE) through the ELECTRA project: Electricity markets and trade in Switzerland and its neighbouring countries: Building a coupled techno-economic modelling framework.

\section{Availability of data and materials}

The datasets used and/or analyzed during the current study are available from the corresponding author on reasonable request, conditional on compliance with the cooperation agreements with all project partners involved.

\section{Competing interests}

The authors declare that they have no competing interests.

\section{Author details}

'Laboratory of Environmental and Urban Economics (LEURE), Ecole

Polytechnique Fédérale de Lausanne (EPFL), Lausanne, Switzerland.

${ }^{2}$ Econability, Mühlethurnen, Switzerland.

\section{Received: 14 December 2017 Accepted: 30 July 2019}

Published online: 13 September 2019

\section{References}

Armington, P. S. (1969). A theory of demand for products distinguished by place of production. International Monetary Fund, 16(1), 159-178.

Böhringer, C., \& Rutherford, T. (2009). Integrated assessment of energy policies: Decomposing top-down and bottom-up. Journal of Economic Dynamics and Control, 33(9), 1648-1661.

Böhringer, C., Wickart, M., \& Müller, A. (2003). Economic impacts of a premature nuclear phase-out in Switzerland: An applied general equilibrium analysis. Swiss Journal of Economics and Statistics, 139(4), 461-505.

Bretschger, L., \& Zhang, L. (2017). Nuclear phase-out under stringent climate policies: A dynamic macroeconomic analysis. The Energy Journal, 38(1), 167194. https://doi.org/10.5547/01956574.38.1.lbre.

Drouet, L., Haurie, A., Labriet, M., Thalmann, P., Vielle, M., \& Viguier, L. (2005). A coupled bottom-up/top-down model for GHG abatement scenarios in the Swiss housing sector. In R. Loulou, Waaub, J.P., \& Zaccour, G. (Eds), Energy and Environment (pp. 27-61). Boston: Springer. doi.org/ https://doi.org/10.1 007/0-387-25352-1_2

Ecoplan. (2012). Energiestrategie 2050 - Volkswirtschaftliche Auswirkungen. Technical report. Swiss Federal Office of Energy.

Fortes, P., Pereira, R., Pereira, A., \& Seixas, J. (2014). Integrated technologicaleconomic modeling platform for energy and climate policy analysis. Energy, 73, 716-730. doi.org/ https://doi.org/10.1016/j.energy.2014.06.075.
Hageman, L. A., \& Young, D. M. (1981). Applied iterative methods. New York: Academic Press INC.

Hoffman, K. C., \& Jorgenson, D. W. (1977). Economic and technological models for evaluation of energy policy. The Bell Journal of Economics, 8(2), 444-466.

International Energy Agency. (2010). World energy outlook 2010. Paris: International Energy Agency (IEA).

Jordan, A., Huitema, D., Van Asselt, H., Rayner, T., \& Berkhout, F. (2010). Climate change policy in the European Union: Confronting the dilemmas of mitigation and adaptation. Cambridge: Cambridge University Press.

Kannan, R., \& Turton, H. (2011). Documentation on the development of the Swiss TIMES electricity model (STEM-E). Technical Report 11. Paul Scherrer Institute.

Labriet, M., Drouet, L., Vielle, M., Haurie, A., Kanudia, A., \& Loulou, R. (2010). Coupled bottom-up and top-down modelling to investigate cooperative climate policies. Les Cahiers du GERAD G-2010-30.

Loulou, R., Goldstein, G., Remne, U., Kanudia, A., \& Lehtila, A. (2005). Documentation for the TIMES model. Technical report. Energy Technology Systems Analysis Programme (ETSAP).

Maire, S. (2016). Coupled energy economic model framework for analyzing Swiss electricity markets in changing policy environments. Ph.D. thesis. Ecole Polytechnique Fédérale de Lausanne (EPFL).

Maire, S., Pattupara, R., Kannan, R., Vielle, M., \& Vöhringer, F. (2015). Electricity markets and trade in Switzerland and its neighbouring countries (ELECTRA) Building a coupled techno-economic modeling framework. Technical report. Swiss Federal Office of Energy.

Maire, S., Vöhringer, F., \& Thalmann, P. (2015). Linking electricity prices and costs in bottom-up top-down coupling under changing market environments. In EPFL Working Paper Series in Environmental and Urban Economics 2015-1. Ecole Polytechnique Fédérale de Lausanne.

Martinsen, T. (2011). Introducing technology learning for energy technologies in a national CGE model through soft links to global and national energy models. Energy Policy, 39(6), 3327-3336.

Pattupara, R. (2016). Long term evolution of the Swiss electricity system under a European electricity market. Ph.D. thesis. ETH Zurich.

Pattupara, R., \& Kannan, R. (2016). Alternative low-carbon electricity pathways in Switzerland and it's neighbouring countries under a nuclear phase-out scenario. Applied Energy, 172, 152-168.

Prognos. (2012). Die Energieperspektiven für die Schweiz bis 2050. Energienachfrage und Elektrizitätsangebot in der Schweiz 2000-2050. Ergebnisse der Modellrechnungen für das Energiesystem. Technical report. Swiss Federal Office of Energy.

Rausch, S., \& Mowers, M. (2014). Distributional and efficiency impacts of clean and renewable energy standards for electricity. Resource and Energy Economics, 36(2), 556-585.

Riekkola, A. K., Berg, C., Ahlgren, E. O., \& Söderholm, P. (2013). Challenges in softlinking: The case of EMEC and TIMES-Sweden. Working Paper 133. National Institute of Economic Research.

Schäfer, A., \& Jacoby, H. D. (2005). Technology detail in a multisector CGE model: Transport under climate policy. Energy Economics, 27(1), 1-24.

Swiss Federal Office of Energy. (2012). Potentiel des énergies renouvelables dans la production d'électricité (Rapport du Conseil fédéral à l'attention de l'Assemblée fédérale, selon l'art. 28b, al. 2, de la loi sur l'énergie). Technical report. Swiss Federal Office of Energy.

Swiss Federal Office of Energy. (2018). In Swiss Federal Office of Energy (Ed.), Schweizerische Elektrizitätsstatistik 2017 / Statistique suisse de l'électricité 2017. Bern.

Vöhringer, F. (2012). Linking the Swiss emissions trading system with the EU ETS: Economic effects of regulatory design alternatives. Swiss Journal of Economics and Statistics, 148(2), 167-196.

Weidmann, N., Kannan, R., \& Turton, H. (2012). Swiss climate change and nuclear policy: A comparative analysis using an energy system approach and a sectoral electricity model. Swiss Journal of Economics and Statistics, 148(2), 275-316

Wene, C.-O. (1996). Energy-economy analysis: linking the macroeconomic and systems engineering approaches. Energy, 21(9), 809-824.

\section{Publisher's Note}

Springer Nature remains neutral with regard to jurisdictional claims in published maps and institutional affiliations. 